\title{
Hyperreninemic Hypoaldosteronism after Chronic Stress in the Rat
}

Greti Aguilera, Alexander Kiss, and Bulbin Sunar-Akbasak

Section on Endocrine Physiology, Developmental Endocrinology Branch, National Institute of Child Health and Human Development, National Institutes of Health, Bethesda, Maryland 20892-1862

\begin{abstract}
The effects of chronic stress on the renin-angiotensin-aldosterone system were studied by analysis of plasma hormone levels, kidney renin mRNA levels, adrenal angiotensin II receptors, and steroidogenesis in rats subjected to repeated immobilization ( $2 \mathrm{~h}$ daily) or intraperitoneal injections of $1.5 \mathrm{M} \mathrm{NaCl}$ for $14 \mathrm{~d}$. $24 \mathrm{~h}$ after the last stress in both stress models, plasma aldosterone levels were reduced in spite of significant increases in plasma renin activity. Repeatedly intraperitoneal hypertonic saline-injected rats showed plasma renin activity responses to acute immobilization similar to controls, but markedly reduced plasma aldosterone responses. Concomitant with the increases in plasma renin activity, renin mRNA levels in the kidney were significantly increased in intraperitoneal hypertonic saline-injected rats, and these increases were prevented by $\beta$-adrenergic receptor blockade with propranolol. In isolated adrenal glomerulosa cells from chronically stressed rats, maximum aldosterone responses to angiotensin II, ACTH, and 8-Br-cAMP were significantly decreased, whereas pregnenolone responses were increased. P450-aldosterone synthetase mRNA levels and binding of ${ }^{125} \mathrm{I}$ - $\left[\mathrm{Sar}^{1}, \mathrm{Ile}^{8}\right.$ ] angiotensin II were significantly reduced in the adrenal zona glomerulosa of stressed rats. These studies show that chronic repeated stress leads to renin stimulation due to sympathetic activation, and inhibition of aldosterone secretion due to inhibition of the late steroidogenic pathway. The data provide evidence for a role of chronic stress in the development of hyperreninemic hypoaldosteronism. (J. Clin. Invest. 1995. 96:15121519.) Key words: renin $\mathrm{mRNA} \cdot$ adrenal $\cdot$ aldosterone synthetase $11 \boldsymbol{\beta}$-hydroxylase $\bullet$ angiotensin II receptors
\end{abstract}

\section{Introduction}

A large body of evidence suggests that a relationship exists between the renin-angiotensin-aldosterone system and the stress response. In addition to activation of the hypothalamicpituitary-adrenal axis and the sympathoadrenal system, which are the major neuroendocrine components of the acute stress response (1-4), most physical-psychologic stress paradigms

Address correspondence to Dr. Greti Aguilera, Section on Endocrine Physiology, Developmental Endocrinology Branch, National Institute of Child Health and Human Development, National Institutes of Health, Building 10, Room 10N262, 10 Center Drive MSC 1862, Bethesda, MD, 20892-1862. Phone: 301-496-2683; FAX: 301-402-0574.

Received for publication 27 February 1995 and accepted in revised form 23 May 1995.

The Journal of Clinical Investigation, Inc.

Volume 96, September 1995, 1512-1519 are also associated with marked increases in plasma renin activity (PRA) ${ }^{1}$ and plasma aldosterone levels (5-10). PRA is elevated after immobilization, handling, and head-up tilt in rats, and arithmetic or intelligence quotient tests in humans (5-10). The mechanism by which PRA increases in response to acute stress involves sympathetic activation, since the increases are attenuated by renal denervation and $\beta$-adrenergic blockers $(5$, 11, 12).

With respect to aldosterone secretion, since plasma levels of the potent aldosterone stimulants, ACTH and angiotensin II (AII), markedly increase after acute stress, it is not surprising that plasma aldosterone levels are also elevated $(8,10)$. However, the control of aldosterone secretion largely depends on the interaction of AII with other regulators (13), and little is known about the consequences of chronic stress on steroidogenesis in the adrenal glomerulosa cell.

Mineralocorticoids, as well as the peripheral and central renin-angiotensin systems, have been implicated in the pathogenesis of cardiovascular disorders such as hypertension and myocardial disease $(14,15)$. Therefore, it is of considerable interest to understand the mechanisms by which chronic stress influences the renin-angiotensin-aldosterone system. The objective of these studies is to investigate the effects of two chronic intermittent stress paradigms, repeated immobilization, and repeated intraperitoneal (i.p.) hypertonic saline injection, on renal renin expression and on adrenal glomerulosa function. The results of these studies show that chronic stimulation of the hypothalamic-pituitary-adrenal axis and sympathetic system during repeated stress leads to hyperreninemic hypoaldosteronism, as a result of increased renin production by the kidney and inhibition of the late steroidogenic pathway.

\section{Methods}

Animal procedures. Male Sprague-Dawley rats (Zivic Miller Laboratories, Zelienople, PA) weighing 320-350 g were housed three per cage in a controlled environment ( $14 \mathrm{~h}$ light; $10 \mathrm{~h}$ dark) with free access to food and water. Rats were handled daily for 3-7 d before the experiment to minimize stress of experimental manipulation and randomly assigned to control and chronically stressed groups. Rats were subjected to chronic intermittent stress by daily i.p. injections of $5 \mathrm{ml}$ of $1.5 \mathrm{M}$ $\mathrm{NaCl}$ ( $7.5 \mathrm{meq} \mathrm{Na} / \mathrm{d}$ ) or immobilization, $2 \mathrm{~h}$ daily, for $14 \mathrm{~d}$. In some experiments, $24 \mathrm{~h}$ after the last hypertonic saline injection, animals were tested for their PRA and aldosterone responses to an acute novel stress and killed by decapitation for blood and tissue collection. In these experiments, rats were subjected to immobilization stress by placing them into a $2.5 \times 6$-in plastic restrainer (Harvard Apparatus Inc., South Natick, MA) for $30 \mathrm{~min}$. 5-8 ml of trunk blood was collected into icecold plastic tubes containing EDTA, centrifuged, and the plasma stored for $2-7 \mathrm{~d}$ at $-70^{\circ} \mathrm{C}$ until analyzed for PRA, aldosterone, corticosterone,

1. Abbreviations used in this paper: AII, angiotensin II; i.p., intraperitoneal; PRA, plasma renin activity. 
and ACTH by radioimmunoassay $(16,17)$. All animal procedures were approved by the National Institute of Child Health and Human Development Animal Care Users Committee.

Determination of renin mRNA by Northern blot. Immediately after decapitation, kidneys were frozen in liquid nitrogen in RNase-free plastic tubes and stored at $-70^{\circ} \mathrm{C}$ until mRNA preparation. $30 \mu \mathrm{g}$ of total RNA prepared from one kidney using kit reagents (RNAzol; Tel-Test, Inc., Friendswood, TX). $30 \mu \mathrm{g}$ of RNA was fractionated in a denaturing formaldehyde-agarose $(1.2 \%)$ gel, transferred to a maximum strength Nytran ${ }^{\circledR}$ Plus membrane (Schleicher \& Schuell, Inc., Keene, $\mathrm{NH}$ ), and hybridized for $18 \mathrm{~h}$ at $42^{\circ} \mathrm{C}$ with $2 \times 10^{7} \mathrm{cpm}$ of a ${ }^{32} \mathrm{P}$-random primed (sp act $1 \times 10^{9} \mathrm{dpm} / \mu \mathrm{g}$ ) 911-bp, pst-sac cDNA fragment of mouse renin-1, kindly provided by Dr. Kenneth Gross (Roswell Park Memorial Institute, Buffalo, NY), in $0.25 \mathrm{ml}$ of hybridization buffer per $\mathrm{cm}^{2}$. The mouse renin-1 cDNA has $84 \%$ homology with rat renin and has been shown to hybridize with a single RNA species in the rat kidney with the expected molecular size for rat renin $(18,19)$. To quantitate the amount of RNA per lane, filters were further hybridized for $3 \mathrm{~h}$ with 2 $\times 10^{6} \mathrm{cpm}$ of a ${ }^{32} \mathrm{P}$-random primed 700-bp cDNA fragment of cyclophilin, prepared from a cDNA clone kindly provided by Dr. L. Charnas, (National Institute of Child Health and Human Development, National Institute of Health). After hybridization, membranes were washed once with $1 \times \mathrm{SSC} / 0.5 \%$ SDS for $20 \mathrm{~min}$ at room temperature, followed by two 20 -min washes with $0.2 \times \mathrm{SSC} / 0.5 \%$ SDS at $68^{\circ} \mathrm{C}$. Membranes were air-dried and exposed overnight to X-OmatAR film (Eastman Kodak Co., Rochester, NY) for 24-48 h for renin and for 6-12 h for cyclophilin. Levels of renin mRNA were measured using a computerized image analysis system (Imaging Research, Inc., St. Catherines, Canada), and the transmittance values of the renin bands were normalized per $100 \mathrm{U}$ of cyclophilin.

AII binding. AII receptors were measured by binding of ${ }^{125}$ I [ $\mathrm{Sar}^{1}{ }^{1}$,Ile $\left.{ }^{8}\right]$ AII to membrane-rich fractions prepared from pools of six adrenal capsules (three rats) per group. Binding assays were performed essentially as previously described (20). Receptor concentration and binding affinity were calculated using the computer program Ligand (21).

In vitro steroid responses in isolated adrenal glomerulosa cells. Adrenals from 10 rats per group were immediately removed after decapitation and collected in medium 199 , containing $3.5 \mathrm{mM} \mathrm{KCl}$ at room temperature. After removing the surrounding fat, adrenal capsules containing the zona glomerulosa were minced and subjected to collagenase digestion and mechanical dispersion as previously described (22). Cells from each experimental group were resuspended in medium 199 containing $4.5 \mathrm{mM} \mathrm{KCl}$ and $0.1 \%$ BSA at a concentration of 50,000 cells/ $\mathrm{ml}$. For aldosterone responses, $1-\mathrm{ml}$ aliquots of the cell suspension were incubated for $2 \mathrm{~h}$ at $37^{\circ} \mathrm{C}$ under $5 \% \mathrm{CO}_{2} / 95 \% \mathrm{O}_{2}$, in the presence of increasing concentrations of ACTH or AII.

To measure the activity of side-chain cleavage enzyme, pregnenolone accumulation was measured after incubation of the cells with maximum stimulatory concentrations of ACTH, AII, or 8-Br-cAMP, in the presence of $1 \mu \mathrm{M}$ of the cyanoketone derivative, WIN 19598, to inhibit $3 \beta$-hydroxysteroid dehydrogenase (23). At the end of the incubation, cells were removed by centrifugation, and the supernatant was stored at $-20^{\circ} \mathrm{C}$ for steroid determination by RIA. Aldosterone was measured using solid-phase kit reagents and ${ }^{125} \mathrm{I}$-labeled aldosterone (Coat-aCount $^{\circledR}$; Diagnostic Products Corp., Los Angeles, CA). Pregnenolone was measured by RIA as previously described (23).

P450-11 -hydroxylase and aldosterone synthetase mRNA levels. Levels of mRNA for cytochrome P450-11 $\beta$-hydroxylase and aldosterone synthetase were measured by in situ hybridization. Adrenal glands were rapidly removed, cleaned from surrounding fat, frozen in embedding matrix (M-1; Lipshaw, Pittsburgh, PA) in dry ice, and stored at $-70^{\circ} \mathrm{C}$ until processing. $12-\mu \mathrm{m}$ sections were cut in a cryostat at $-18^{\circ} \mathrm{C}$, thawed, and mounted on gelatin double-coated slides, and stored at $-70^{\circ} \mathrm{C}$ until hybridization.

48-mer oligonucleotide probes (custom synthesis by Synthecell Corp., Rockville, MD) complementary to bp 863-900 of P450-aldoste-
Table I. Effect of Repeated i.p. Hypertonic Saline Injection or Immobilization, 2 h Daily, for $14 \mathrm{~d}$, on Basal Plasma Levels of Aldosterone, Corticosterone, and Plasma Renin Activity in the Rat

\begin{tabular}{lrcc}
\hline & Controls & Immobilization & $\begin{array}{c}\text { i.p. Hypertonic } \\
\text { saline }\end{array}$ \\
\hline Corticosterone $(\mu \mathrm{g} / \mathrm{dl})$ & $1.3 \pm 0.5$ & $2.7 \pm 0.6$ & $3.5 \pm 0.3^{*}$ \\
ACTH $(\mathrm{pg} / \mathrm{ml})$ & $65.3 \pm 5.6$ & $77.5 \pm 7.8$ & $75.7 \pm 5.3$ \\
PRA $(\mathrm{ng} / \mathrm{ml}$ per h) & $1.6 \pm 0.2$ & $2.7 \pm 0.3^{*}$ & $3.3 \pm 0.4^{*}$ \\
Aldosterone (ng/dl) & $11.4 \pm 1.3$ & $7.2 \pm 0.3^{*}$ & $6.9 \pm 0.4^{*}$ \\
& & & \\
\hline
\end{tabular}

Rats were killed by decapitation $24 \mathrm{~h}$ after the last stress exposure. $* P<0.01$ compared with controls.

rone synthetase cDNA, and bp 863-897 of P450-11 $\beta$-hydroxylase cDNA were labeled using ${ }^{35}$ S-dATP (NEN Research Products, Boston, MA) and terminal deoxynucleotide transferase (Bethesda Research Laboratories, Gaithersburg, MD). Sections were hybridized essentially as previously described (24) for $18 \mathrm{~h}$ at $40^{\circ} \mathrm{C}$, washed, and exposed for $48 \mathrm{~h}$ (aldosterone synthetase) or $4 \mathrm{~h}$ ( $11 \beta$-hydroxylase) to Hyperfilmbeta max (Amersham Corp., Arlington Heights, IL). Tissue mRNA levels were estimated using a computerized image analysis system (Image; Imaging Research Inc.). Mean light transmittance was converted to disintegrations per minute per microgram tissue by comparing the values with the transmittance values of ${ }^{35} \mathrm{~S}$ standards of known activity exposed in the same film. Adrenal sections from all groups in each experiment were hybridized and exposed to film together. Hybridization of adrenal sections with sense, $11 \beta$-hydroxylase and aldosterone synthetase, oligonucleotides was not distinguishable from the film background.

Statistical analysis. Data are presented as the mean and SEM of the number of observations indicated in Results or figure legends. Statistical significance of the differences between experimental groups was determined by ANOVA followed by Sheffe's $F$ test for multiple group comparisons.

\section{Results}

The effects of repeated stress for $14 \mathrm{~d}$ on basal levels of plasma ACTH, corticosterone, aldosterone, and PRA are shown in Table I. $24 \mathrm{~h}$ after the last exposure to immobilization or i.p. hypertonic saline injection, plasma ACTH levels were similar to those in controls, while plasma corticosterone levels were significantly elevated in rats subjected to repeated i.p. hypertonic saline injection but not after repeated immobilization. Basal plasma aldosterone levels were significantly reduced in both chronically stressed groups, whereas PRA was significantly elevated.

To determine the responsiveness to acute stimulation in chronically stressed rats, PRA and plasma aldosterone levels were measured after $30 \mathrm{~min}$ immobilization in rats subjected to repeated i.p. hypertonic saline injection (Fig. 1). In spite of increased basal PRA in rats receiving repeated i.p. hypertonic saline injections (Table I), acute stress ( $30 \mathrm{~min}$ immobilization) resulted in similar responses in both groups, with increases from $1.1 \pm 0.2$ to $12.8 \pm 4 \mathrm{ng} / \mathrm{ml}$ per $\mathrm{h}$ in controls, and from $3.3 \pm 0.4$ to $13.8 \pm 2 \mathrm{ng} / \mathrm{ml}$ per $\mathrm{h}$ in the chronically stressed group. On the other hand, plasma aldosterone responses to immobilization were significantly reduced in chronically stressed rats, with increases from $11.4 \pm 1.3$ to $48.1 \pm 5.5 \mathrm{ng} / \mathrm{dl}$ in controls, and from $6.9 \pm 0.4$ to $22.9 \pm 4.1 \mathrm{ng} / \mathrm{dl}$ in hypertonic saline-injected rats.

Renin mRNA in the kidney. The basis for the increased PRA 


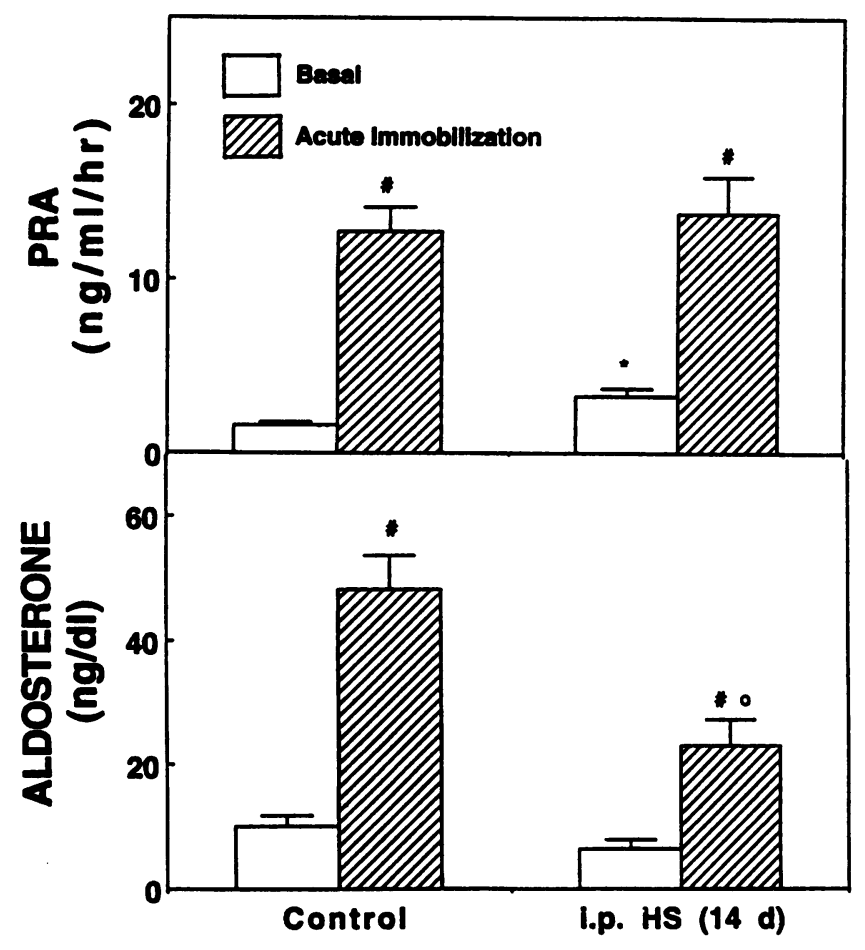

Figure 1. PRA and plasma aldosterone levels in response to acute immobilization in controls and rats subjected to repeated i.p. hypertonic saline injection. Rats were injected with $5 \mathrm{ml}$ i.p. of $0.9 \%$ saline (controls) or $1.5 \mathrm{M} \mathrm{NaCl}$ (i.p. $H S$ ) for $14 \mathrm{~d}$. Rats were killed $24 \mathrm{~h}$ after the last injection in basal conditions or after $30 \mathrm{~min}$ immobilization (acute immobilization). Bars represent the mean and SEM of the values obtained in $12-18$ rats per group. $" P<0.01$ vs basal; ${ }^{*} P<0.01$ vs basal control; ${ }^{\circ} P<0.01$ vs control immobilization.

after chronic stress was studied by analysis of renin mRNA levels in kidneys from rats subjected to repeated stress or increased sodium intake (Fig. 2). Northern blot analysis of total kidney RNA from control rats revealed a $1.6-\mathrm{kb}$ band consistent with the expected molecular size of renin mRNA in the rat. After repeated immobilization for $14 \mathrm{~d}$, renin mRNA levels showed a tendency to increase from $32.8 \pm 3.5$ to $40.4 \pm 1.2$ arbitrary $\mathrm{U}$ but were not significantly different from controls. On the other hand, repeated i.p. hypertonic saline injection resulted in significant increases in renin mRNA in the kidney $(53.3 \pm 2.2$ $\mathrm{U}, P<0.01$ ), while administration of similar amounts of $\mathrm{NaCl}$ in the drinking water for $12 \mathrm{~d}$ caused a marked $94 \%$ decrease in renin mRNA levels $(1.9 \pm 1.8 \mathrm{U})$.

To determine whether sympathetic activation during chronic stress is responsible for the increased levels of renin mRNA in the kidney, rats were implanted with propranolol pellets, 200 $\mathrm{mg}$, subcutaneously (Innovative Research, Toledo, $\mathrm{OH}$ ) $24 \mathrm{~h}$ before initiation of repeated i.p. hypertonic saline injections. As shown in Table II, $\beta$-adrenergic blockade with propranolol had no effect on the decrease in plasma aldosterone but markedly attenuated the increase in basal PRA and renin mRNA in the kidney observed after i.p. hypertonic saline injection.

Steroid responses in isolated glomerulosa cells. As shown in Fig. 3, aldosterone production in response to ACTH and AII was reduced in collagenase-dispersed adrenal glomerulosa cells from chronically stressed rats. In three experiments, repeated

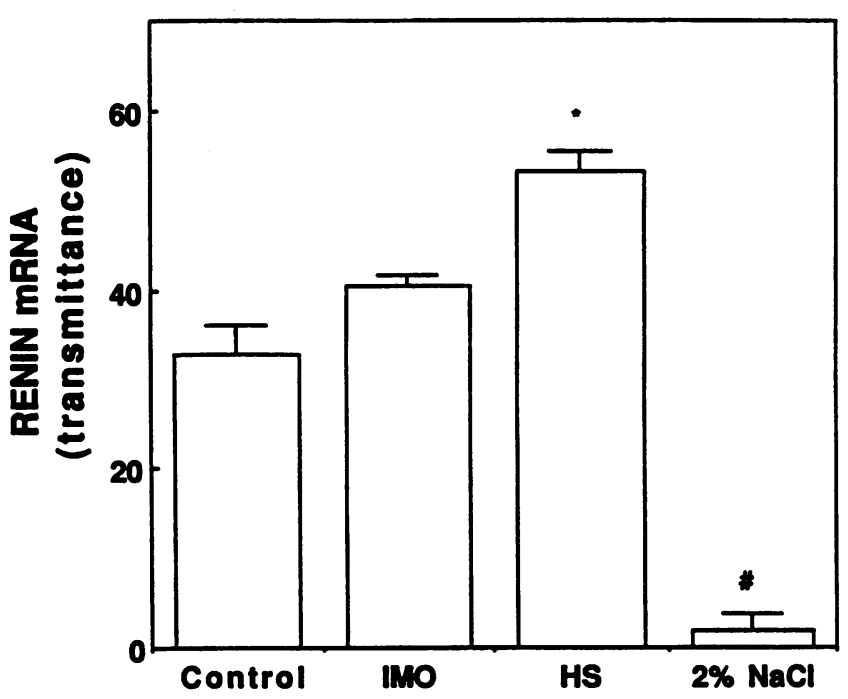

Figure 2. Effect of chronic stress on renin mRNA in the rat kidney. Rats were subjected to repeated immobilization, $2 \mathrm{~h}$ daily $(I M O)$, or repeated i.p. hypertonic saline injection $(H S)$ for $14 \mathrm{~d}$, or $2 \%$ saline intake for $12 \mathrm{~d}$ before collecting the kidneys for mRNA determination. Bars are the mean and SEM of the data obtained from Northern blot analyses in six rats per group.

immobilization caused a 28 and $24 \%$ decrease to maximum stimulatory concentrations of ACTH and AII, respectively. A more marked reduction was observed in cells from rats subjected to repeated i.p. hypertonic saline injection, with 47 and $46 \%$ decreases in the responses to ACTH and AII. No significant differences in the $\mathrm{ED}_{50}$ of the aldosterone responses to ACTH or AII were observed between the groups (Table III). Aldosterone responses to $5 \mathrm{mM}$ 8-Br-cAMP were also significantly smaller in cells from chronically stressed rats compared to those in cells from control rats, with increases from $1.7 \pm 0.1$ to $12.4 \pm 1.5 \mathrm{ng} / \mathrm{dl}$ in controls, $1.5 \pm 0.1$ to $8.1 \pm 0.5 \mathrm{ng} / \mathrm{dl}$ in repeated immobilization, and $1.8 \pm 0.3$ to $6.3 \pm 0.9$ in i.p. hypertonic saline injection.

In contrast, the capacity of the cells to produce pregnenolone

Table II. Effect of $\beta$-adrenergic Blockade on the Effects of Repeated i.p. Hypertonic Saline Injection for 14 d, on Basal Plasma Levels of Aldosterone and Plasma Renin Activity, and Renin MRNA in the Kidney

\begin{tabular}{lrrrrr}
\hline & \multicolumn{2}{c}{ Controls } & & \multicolumn{2}{c}{ i.p. Hypertonic saline } \\
\cline { 2 - 3 } \cline { 5 - 6 } & \multicolumn{1}{c}{ Placebo } & Propranolol & & Placebo & Propranolol \\
\hline PRA (ng/ml per h) & $1.8 \pm 0.7$ & $1.2 \pm 0.6$ & & $4.1 \pm 0.5^{*}$ & $1.9 \pm 0.6^{\ddagger}$ \\
Aldosterone (ng/dl) & $10.4 \pm 2.3$ & $11.1 \pm 1.9$ & & $6.9 \pm 0.4^{*}$ & $5.8 \pm 0.7$
\end{tabular}

Renin mRNA (AU/

$100 \mathrm{AU}$ cyclophilin) $\quad 34.4 \pm 5.9 \quad 29.3 \pm 2.5 \quad 60.2 \pm 5.9 \quad 43.4 \pm 6.2^{\ddagger}$

Rats were implanted subcutaneously with $200 \mathrm{mg}$ propranolol or placebo pellets (Innovative Research), $24 \mathrm{~h}$ before initiating repeated i.p. hypertonic saline injections and killed by decapitation $24 \mathrm{~h}$ after the last stress exposure. Values are the mean and SEM of the results in six rats per group. ${ }^{*} P<0.01$ compared with controls; ${ }^{\ddagger} P<0.01$ compared with placebo; $\mathrm{AU}$, arbitrary units. 


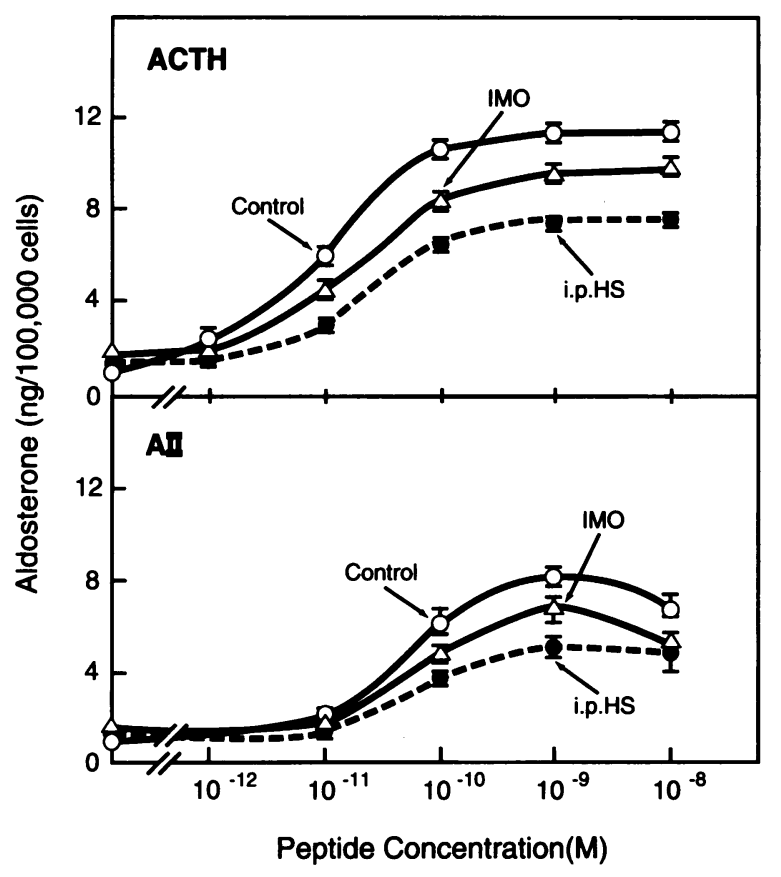

Figure 3. Aldosterone responses to ACTH (top) and AII (bottom) in isolated adrenal glomerulosa cells from control rats, and rats subjected to repeated immobilization (IMO) or i.p. hypertonic saline injection (i.p. $H S$ ) for $14 \mathrm{~d}$. Data points are the mean and SEM of triplicate incubations from one of three similar experiments.

was increased in cells from chronically stressed rats (Fig. 4). Basal pregnenolone accumulation was similar in cells from controls, immobilized, and i.p. hypertonic saline-injected rats $(49.3 \pm 8.7,46.3 \pm 6.4$, and $48.6 \pm 8.0$, respectively $)$, whereas responses to AII were increased by 28 and $35 \%$, to ACTH by 34 and $63 \%$, and to 8 -Br-cAMP by 42.2 and $71 \%$, respectively.

Adrenal levels of $P 450-11 \beta$ and P450-aldosterone synthetase mRNA. The cellular mechanism of the inhibition of aldosterone secretion during chronic stress was studied by analysis of mRNA levels of enzymes of the late steroidogenic pathway in the adrenal. In situ hybridization analysis of the distribution of aldosterone synthetase and $11 \beta$-hydroxylase mRNAs in the adrenal of control rats revealed differential expression of these enzymes in the adrenal cortex. While aldosterone synthetase

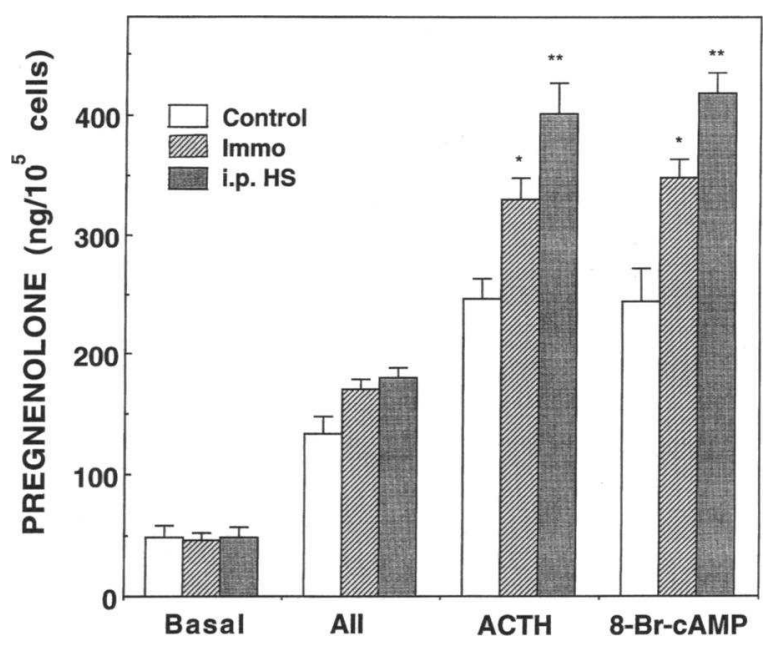

Figure 4. Stimulation of pregnenolone production by ACTH, AII, and 8-Br-cAMP in collagenase dispersed adrenal glomerulosa cells from controls and rats subjected to repeated i.p. hypertonic saline injection for $14 \mathrm{~d}$. Bars represent the mean and SEM of values obtained in three cell preparations. ${ }^{*} P<0.05$ vs control; ${ }^{* *} P<0.01$ vs control.

mRNA was detectable only in the subcapsular outermost portions of the cortex corresponding to the zona glomerulosa, P450$11 \beta \mathrm{mRNA}$ was absent in the zona glomerulosa but was present throughout the inner zones of the cortex (Fig. 5).

After repeated immobilization or i.p. hypertonic saline injection, the intensity of hybridization for P450-11 $\beta$ mRNA in the adrenal zona fasciculata was similar to that in controls. However, the labeled area was significantly increased in adrenals from the chronically stressed groups, especially after repeated i.p. hypertonic saline injection, where P450-11 $\beta$-hydroxylase hybridization appear to overlap with the area hybridized with aldosterone synthetase in the zona glomerulosa (Fig. 5). Computer analysis of the areas enclosed by hybridization for both enzymes' mRNAs in consecutive adrenal sections in 12 adrenals per group showed that in control adrenals the area delineated by aldosterone synthetase was significantly larger than that circumscribed by $\mathrm{P} 450-11 \beta$-hydroxylase $(3,105 \pm 92$

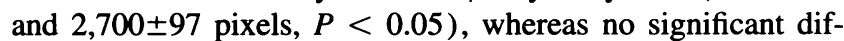
ference was present after repeated i.p. hypertonic saline injection $(3,062 \pm 105$ and $3,052 \pm 81$ pixels $)$, or immobilization

Table III. Effect of Repeated Immobilization or Repeated i.p. Hypertonic Saline Injection for 14 d on In Vitro Aldosterone Responses to ACTH and AII in Collagenase Dispersed Adrenal Glomerulosa Cells

\begin{tabular}{|c|c|c|c|c|c|}
\hline & \multicolumn{5}{|c|}{ Aldosterone production } \\
\hline & \multicolumn{3}{|c|}{ Maximum } & \multicolumn{2}{|c|}{$\mathrm{ED}_{\text {so }}$} \\
\hline & Basal & ACTH & AII & АCTH & AII \\
\hline & \multicolumn{3}{|c|}{ ng/10 cells } & \multicolumn{2}{|c|}{$n M$} \\
\hline Control & $1.5 \pm 0.2$ & $11.1 \pm 0.9$ & $8.7 \pm 0.6$ & $0.06 \pm 0.03$ & $0.6 \pm 0.3$ \\
\hline Immobilization $(2 \mathrm{~h} \times 14 \mathrm{~d})$ & $1.9 \pm 0.3$ & $8.0 \pm 0.4^{* \ddagger}$ & $6.2 \pm 0.2^{* \ddagger}$ & $0.06 \pm 0.03$ & $0.7 \pm 0.3$ \\
\hline i.p. Hypertonic saline (daily for $14 \mathrm{~d}$ ) & $1.5 \pm 0.3$ & $6.0 \pm 0.6 * \S$ & $4.5 \pm 0.7 * \S$ & $0.07 \pm 0.03$ & $0.7 \pm 0.3$ \\
\hline
\end{tabular}

Values are the mean and SEM of the results in dose response curves in three adrenal cell preparations per experimental group. ${ }^{*} P<0.01$ vs basal; ${ }^{\ddagger} P<0.05$ vs controls; ${ }^{8} P<0.01$ vs controls. 
P450-ALDO MRNA
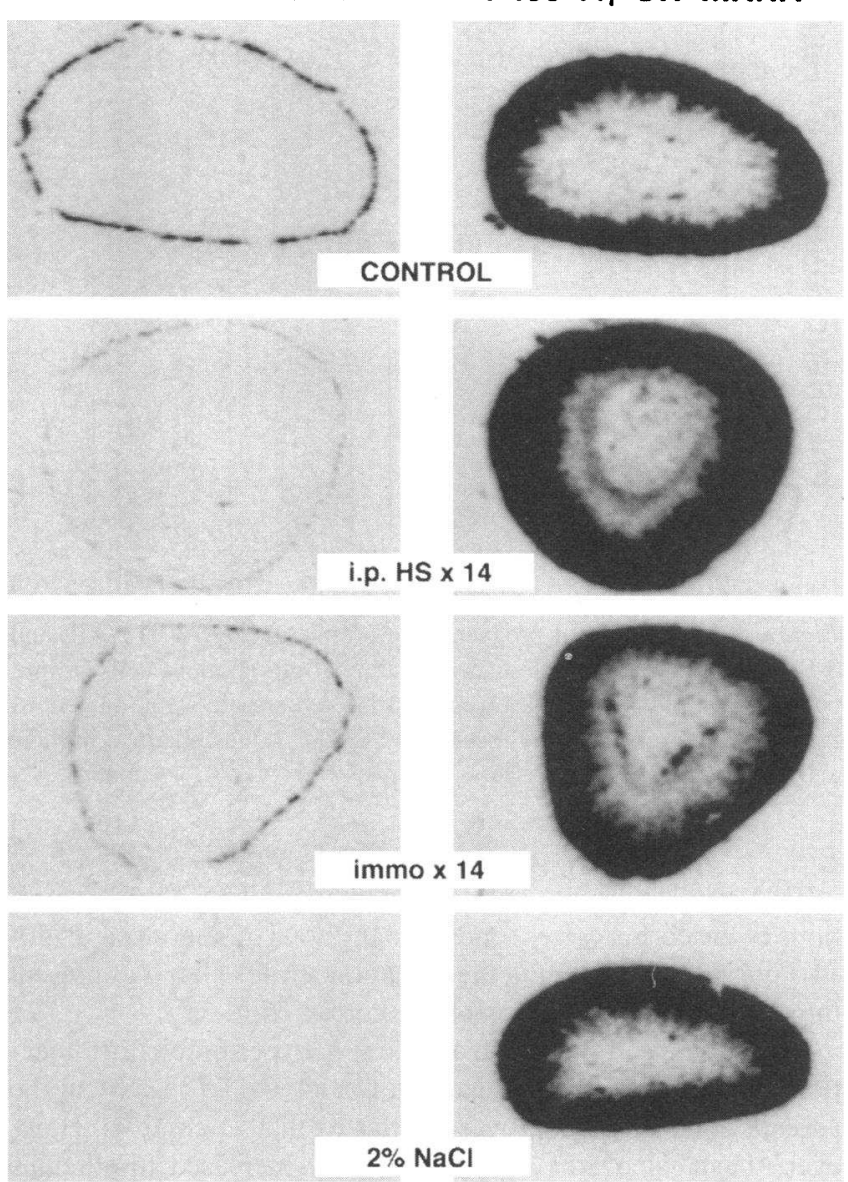

Figure 5. In situ hybridization of P450-aldosterone synthetase ( $P 450$ $A L D O)$ and $11 \beta$-hydroxylase (P450-11 $\beta \mathrm{OH})$ mRNAs in consecutive adrenal sections of control rats, and rats subjected to repeated i.p. hypertonic saline injection (i.p. $H S \times 14$ ), or immobilization $($ immo $\times 14$ ) for $14 \mathrm{~d}$, or $2 \%$ saline intake $(2 \% \mathrm{NaCl})$ for $12 \mathrm{~d}$.

$(2,951 \pm 84$ and $2,783 \pm 103$ pixels $)$. In adrenals from rats receiving $2 \%$ saline as drinking fluid, there was a small but significant increase in hybridization intensity of $\mathrm{P} 450-11 \beta$-hydroxylase (Fig. $6 \mathrm{~A}$ ). Consistent with the decreases in aldosterone secretion in vivo and in vitro, P450-aldosterone synthetase mRNA levels in the zona glomerulosa were markedly decreased in adrenals from both groups of chronically stressed rats, with a $58 \%$ reduction after repeated immobilization and an $86 \%$ reduction after repeated i.p. hypertonic saline injection (Figs. 5 and $6 \mathrm{~B})$. As expected, administration of $2 \%$ saline in the drinking water caused a marked decrease $(87 \%)$ in $\mathrm{P} 450$-aldosterone synthetase mRNA levels.

Effect of repeated stress on adrenal capsular AII receptors. Repeated stress caused a significant reduction in the concentration of AII-binding sites in adrenal capsular membrane-rich fractions (Fig. 7). Scatchard analysis of the binding data in three experiments revealed that binding affinity was unchanged $(0.8 \pm 0.1,1.2 \pm 0.3$, and $0.9 \pm 0.2 \mathrm{nM}$ for controls, immobilization, and i.p. hypertonic saline injection, respectively), while receptor concentration decreased from control values of $1,378 \pm 68 \mathrm{fmol} / \mathrm{mg}$ to $1,075 \pm 43$ and $693 \pm 49$ after repeated immobilization or i.p. hypertonic saline injections, respectively.

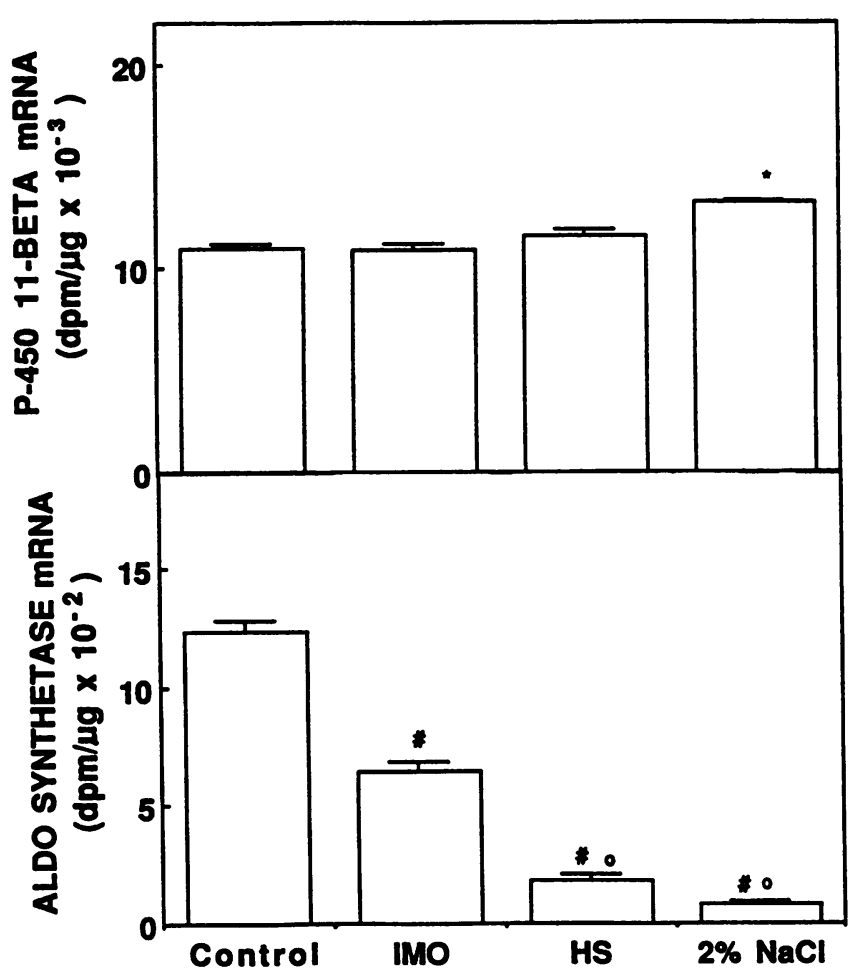

Figure 6. Effect of repeated immobilization (IMO) or hypertonic saline injection $(H S)$, or $2 \%$ saline intake for $12 \mathrm{~d}$ on P450-11 $\beta$-hydroxylase mRNA $(A)$, and P450-aldosterone synthetase mRNA $(B)$. Bars represent the mean and SEM of the values obtained by in situ hybridization in six rats per group. ${ }^{*} P<0.05$ higher than controls; ${ }^{*} P<0.01$ lower than controls; ${ }^{\circ} P<0.01$ lower than IMO.

\section{Discussion}

These studies demonstrate that chronic physical-psychological stress leads to sustained stimulation of renin expression in the kidney with a concomitant reduced capacity of the adrenal zona glomerulosa to secrete aldosterone. These abnormalities are similar to those observed in some critically ill patients (2527) and in models of tumor-induced hypercalcemia in the rat (28), suggesting that chronic stress of severe illness may account for the hyperreninemic hypoaldosteronism observed in these patients.

Studies in rats and humans have shown that increases in PRA are a component of the acute stress response (5-9). The present demonstration of elevated renin mRNA levels in the kidney of repeatedly stressed rats indicates that increased renin synthesis is at least partially responsible for the increases in PRA. In addition, it is clear from these experiments that intermittent stressful stimuli are capable of inducing chronic elevations in renin activity. The ability of the $\beta$-adrenergic antagonist, propranolol, to prevent the increases in basal PRA and kidney renin strongly suggests that sympathetic activation is responsible for the increased renin expression and secretion. Similarly, the increases in PRA in response to acute immobilization and head-up tilt are suppressed by propranolol (12) indicating that PRA responses to acute stress are also mediated by sympathetic activation. However, it is not possible to rule out the possibility that stress-induced activation of serotoninergic pathways known 


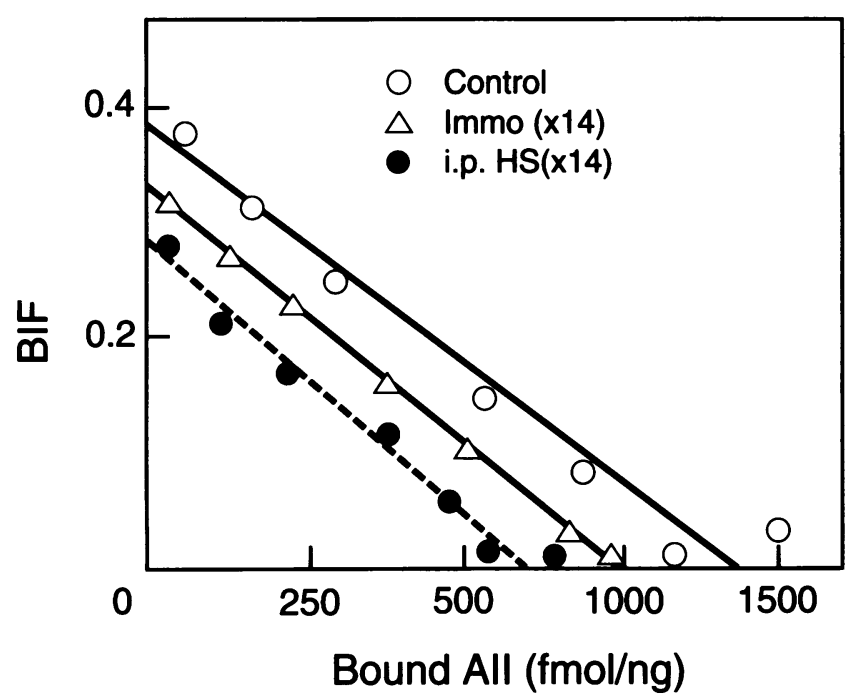

Figure 7. Effect of repeated immobilization, 2 h daily, or i.p. hypertonic saline injection for $14 \mathrm{~d}$, on AII receptors in adrenal capsular membranerich fractions. Data points are the mean of duplicate incubations from one of three similar experiments.

to influence renin secretion $(29,30)$ may also contribute to the increased renin expression in the kidney.

It is noteworthy that the highest stimulation of renin mRNA and PRA was observed after repeated i.p. hypertonic saline injections, despite a considerable degree of sodium loading (31). The daily amount of sodium administered with the i.p. injections $(420 \mathrm{mg})$ is similar to the daily sodium intake in rats drinking $2 \% \mathrm{NaCl}$ solution, in which renin mRNA levels in the kidney were markedly reduced. This indicates that sympathetic stimulation during repeated stress is able to overcome the inhibitory effect of sodium loading on renin expression.

The rate-limiting enzyme in aldosterone biosynthesis is aldosterone synthetase, which catalyzes the conversions of deoxycorticosterone to corticosterone and from corticosterone to aldosterone in the zona glomerulosa of the adrenal $(13,32)$. The amino acid sequence of aldosterone synthetase shows $>80 \%$ homology with $11 \beta$-hydroxylase, which converts deoxycorticosterone to corticosterone or deoxycortisol to cortisol in the zona fasciculata (32). The topographic distribution of the mRNAs for both enzymes shown by the present in situ hybridization studies suggests that in normal conditions $11 \beta$-hydroxylase is exclusively located in the zona fasciculata. A differential distribution of these enzymes is evident in recent detailed in situ hybridization studies using light microscopy analysis of emulsion dipped sections in which autoradiographic grains corresponding to aldosterone synthetase mRNA overlay cells of the zona glomerulosa, whereas $11 \beta$-hydroxylase mRNA is in the zona fasciculata and absent in glomerulosa cells (Feuillan, P., and G. Aguilera, manuscript in preparation). In contrast to control rats, the present studies suggest that in chronically stressed rats $11 \beta$-hydroxylase is also present in the subcapsular area of the adrenal cortex. Although in these experiments technical problems prevented light microscopic examination of the slides, the overlap between the areas hybridized with both probes in the adrenal of chronically stressed rats strongly suggests that $11 \beta$-hydroxylase mRNA has been induced in adrenal glomerulosa cells. An analogous situation has been shown by in vitro studies in which $17 \beta$-hydroxylase, an adrenal fasciculata enzyme, is induced in bovine adrenal glomerulosa cells exposed to ACTH during culture $(33,34)$. In the present experiments, basal plasma ACTH levels measured $24 \mathrm{~h}$ after the last stress exposure were normal. However, the repeated increases in circulating ACTH after each stress exposure $(1,4,31,35)$ are sufficient to induce fasciculata phenotype in adrenal glomerulosa cells, as suggested by the ability of daily pulses of low concentrations of ACTH in cultured bovine adrenal glomerulosa cells to progressively increase cortisol production and $17 \beta$ hydroxylase mRNA levels while decreasing aldosterone output (34).

The aldosterone responses of isolated adrenal glomerulosa cells as well as the decreases in aldosterone synthetase mRNA levels indicate that the reduced capacity of the adrenal of chronically stressed rats to secrete aldosterone is due to inhibition of the late biosynthetic pathway. The inhibition of aldosterone secretion in the presence of increased PRA suggests the involvement of an inhibitory factor, capable of counteracting the stimulatory action of AII. Circulating levels of a number of factors with known or potential inhibitory activity on aldosterone secretion, such as ACTH, dopamine, atrial natriurectic peptide, cytokines, and others, increase in response to stress $(1-4,10,36)$.

The abnormalities of adrenal zona glomerulosa function in the present experiments resemble the changes observed after chronic ACTH administration (37), suggesting that stress-induced ACTH secretion is responsible for decreased aldosterone secretion. Although ACTH is a potent stimulant of aldosterone secretion in acute conditions, prolonged administration in humans or rats causes a decline of plasma aldosterone to basal levels (37-41), associated with decreases in adrenal glomerulosa AII receptors, increases in side-chain cleavage activity, and marked decreases in aldosterone synthetase activity (37). Studies in humans have shown that prolonged ACTH administration inhibits aldosterone secretion in spite of high renin activity (41), which would be homologous to the present experimental conditions. Supporting the participation of ACTH, the severity of the adrenal changes during chronic stress appear to be proportional to the magnitude of the ACTH responses to stress. In this regard, the more profound inhibition of adrenal glomerulosa function was observed after repeated i.p. hypertonic saline injection, a stress paradigm in which there is no desensitization of the ACTH responses to the repeated stimulus (31), whereas a milder inhibition was found after chronic immobilization, a stress model in which the magnitude of ACTH responses decreases with repeated exposure to the stimulus $(4,35)$. A similar mechanism for the hypoaldosteronism has been postulated in critically ill patients, in whom increased ACTH secretion may lead to adaptational changes in the adrenal with a shift of steroidogenesis from mineralocorticoid to glucocorticoid secretion (27).

In addition to ACTH, other factors such as catecholamines, atrial natriuretic peptide, and cytokines may contribute to the inhibition of adrenal glomerulosa function during chronic stress. The stress response is characterized by marked release of norepinephrine from sympathetic terminals and epinephrine and dopamine from the adrenal medulla (1-3). Since dopaminergic mechanisms are involved in reducing the sensitivity of the adrenal glomerulosa to AII during high sodium intake (42), dopamine may contribute to the inhibition of aldosterone secretion 
after repeated stress. With respect to catecholamines, while some studies in humans indicate that infusion of norepinephrine stimulates aldosterone secretion through stimulation of renin, other studies suggest an inhibitory effect $(43,44)$. In vitro studies have shown that catecholamines have no effect on aldosterone production in freshly prepared bovine $(45,46)$, rat, or human (47) adrenal glomerulosa cells, whereas a stimulatory effect has been observed in cultured bovine cells (46). Atrial natriuretic peptide should also be considered as a potential inhibitor of adrenal glomerulosa function during chronic stress. Atrial natriuretic peptide is a potent inhibitor of aldosterone secretion $(17,48)$, and plasma levels increase during acute immobilization (10), and presumably after hypertonic saline injection. Other inhibitors of aldosterone secretion including cytokines, TNF, and IL-1 (49) are unlikely to play a role in the present experiments, but they could alter adrenal function in other chronic stress conditions such as inflammatory diseases or severe illness.

In conclusion, these studies show that chronic repeated stress leads to sustained stimulation of the juxtaglomerular cells due to sympathetic activation and inhibition of aldosterone secretion due to inhibition of the late steroidogenic pathway. Although the relative role of ACTH and other factors in the inhibition of aldosterone secretion remains to be elucidated, the alterations of the renin-angiotensin-aldosterone system observed in the present experimental conditions provide evidence for a role of chronic stress in the pathogenesis of cardiovascular disease.

\section{Acknowledgments}

We thank Dr. Kenneth Gross for kindly providing the renin cDNA clone and Dr. Lawrence Charnas for the cyclophilin clone.

\section{References}

1. Darlington, D. N., L. C. Keil, and M. F. Dallman. 1989. Potentiation of hormonal responses to hemorrhage and fasting, but not to hypoglycemia in conscious adrenalectomized rats. Endocrinology. 125:1398-1406.

2. Udelsman, R., J. A. Norton, S. E. Jelenich, D. S. Goldstein, W. M. Linehan, L. D. Loriaux, and G. P. Chrousos. 1987. Responses of the hypothalamic-pituitary-adrenal and renin angiotensin axes and the sympathetic system during controlled surgical and anesthetic stress. J. Clin. Endocrinol. \& Metab. 64:986-994.

3. Aguilera, G. 1994. Regulation of pituitary ACTH secretion during chronic stress. Front. Neuroendocrinol. 15:321-350.

4. Cryer, P. E. 1980. Physiology and pathophysiology of the human sympathoadrenal neuroendocrine system. N. Engl. J. Med. 303:436-444.

5. Sigg, E. B., K. L. Keim, and T. D. Sigg. 1978. On the mechanism of renin release of restraint stress in rats. Pharmacol. Biochem. Behav. 8:47-50.

6. Jindra, A., Jr., and R. Kvetnansky. 1982. Stress-induced activation of inactive renin. J. Biol. Chem. 257:5997-5999.

7. Ganong, W. F., and C. Barbieri. 1982. Neuroendocrine components in the regulation of renin secretion. In Frontiers in Neuroendocrinology, Vol. 7. W. F. Ganong and L. Martini, editors. Raven Press, Ltd., New York. 231-262.

8. Meyerhoff, J. L., M. A. Oleshanky, K. T. Kalogeras, E. H. Mougey, G. P. Chrousos, and L. G. Granger. 1990. Neuroendocrine responses to emotional stress: possible interactions between circulating factors and anterior pituitary hormone release. In Circulating Regulatory Factors and Neuroendocrine Function. J. C. Porter, and D. Jezova, editors. Plenum Publishing Corp., New York. 91-111.

9. Carey, R. M., C. E. Rose Jr., and M. J. Peach. 1989. Role of the renin angiotensin system in stress. In Stress: Neurochemical and Humoral Mechanisms. G. R. Van Loon, R. Kvetnansky, R. McCarty, and J. Axelrod, editors. Gordon and Breach Science Publishers Inc., New York. 833-844.

10. Macho, L., R. Kvetnansky, M. Fickova, D. Jezova, B. Lichardus, and R. M. Carey. 1992. Plasma levels of catecholamines, aldosterone, atrial natriuretic peptide, and renin activity during immobilization stress in rats. In Stress: Neuroendocrine and Molecular Approaches. R. Kvetnansky, R. McCarty, and J. Axelrod, editors. Gordon and Breach Science Publishers Inc., New York. 187-195.
11. Zimerman, H., and W. F. Ganong. 1980. Pharmacological evidence that stimulation of central serotoninergic pathways increases renin secretion. Neuroendocrinology. 30:101-107.

12. Golin, R. M. A., E. Gotoh, S. I. Said, and W. F. Ganong. 1988. Pharmacological evidence that the sympathetic nervous system mediates the increase in renin secretion produced by immobilization and head up tilt in rats. Neuropharmacology. 27:1209-1213.

13. Aguilera, G. 1993. Factors controlling steroid biosynthesis in the zona glomerulosa of the adrenal. J. Steroid Biochem. Mol. Biol. 45:147-151.

14. Dzau, V. J. 1987. Implications of local angiotensin II production in cardiovascular physiology and pharmacology. Am. J. Cardiol. 59:59A-65A

15. Weber, K. T., Y. Sun, and E. Guarda. 1994. Structural remodeling in hypertensive heart disease and the role of hormones. Hypertension (Dallas). 23:869-877.

16. Hauger, R. L., M. A. Millan, M. Lorang, J. P. Harwood, and G. Aguilera. 1988. Corticotropin releasing factor receptors and pituitary adrenal responses during immobilization stress. Endocrinology. 123:396-405.

17. Aguilera, G. 1987. Differential effects of atrial natriuretic factor on AIand ACTH-stimulated aldosterone secretion. Endocrinology. 120:299-304.

18. Burnham C. E., C. L. Hawelu-Johnson, B. M. Frank, and K. R. Lynch. 1987. Molecular cloning of rat renin cDNA and its gene. Proc. Natl. Acad. Sci. USA. 84:5605-5609.

19. Nakamura N., F. Soubrier, J. Menard, J.-J. Panthier, F. Rougeon, and P. Corvol. 1985. Non-proportional changes in plasma renin concentration, renal renin content, and rat renin messenger RNA. Hypertension (Dallas). 7:855-859.

20. Glossmann, H., A. Baukal, G. Aguilera, and K. J. Catt. 1985. Radioligand assay of angiotensin II receptors. Methods Enzymol. 109:110-126.

21. Munson, P., and D. Rodbard. 1980. Ligand: a versatile computarized approach for characterization of ligand binding systems. Anal. Biochem. 107:220239.

22. Douglas, J., G. Aguilera, T. Kondo, and K. J. Catt. 1978. Angiotensin II receptors and aldosterone production in rat adrenal glomerulosa cells. Endocrinology. 102:685-992.

23. Aguilera, G., and K. J. Catt. 1979. Loci of action of regulators of aldosterone biosynthesis in isolated adrenal glomerulosa cells. Endocrinology. 104:10461052.

24. Harbuz, M., and S. L. Lightman. 1989. Responses of hypothalamic and pituitary mRNA to physical and psychological stress in the rat. J. Endocrinol. 122:705-711

25. Zipser, R. D., M. K. Davenport, K. L. Martin, M. L. Tuck, N. E. Warner, R. R. Swinney, C. L. Davis, and R. Horton. 1981. Hyperreninemic hypoaldosteronism in the critically ill: a new entity. J. Clin. Endocrinol. \& Metab. 53:867873.

26. Stern, N., F. W. Beck, J. R. Sowers, M. Tuck, W. A. Hsueh, and R. D. Zipser. 1983. Plasma corticosteroids in hyperreninemic hypoaldosteronism: evidence for diffuse impairment of the zona glomerulosa. J. Clin. Endocrinol. \& Metab. 57:217-220.

27. Parker, L. N., E. R. Levin, and E. T. Lifrak. 1985. Evidence for adrenal adaptation to severe illness. J. Clin. Endocrinol. \& Metab. 60:947-952.

28. Sowers, J. R., E. Sollars, M. D. Nyby, K. Jasberg, and M. L. Tuck. 1981. Hyperreninemic hypoaldosteronism in association with neoplasia induced hypercalcemia in the Fisher rat. Metab. Clin. Exp. 30:987-952.

29. Van de Kar, L. D., S. A. Lawrence, C. R. McWilliams, K. Kunimoto, and C. L. Bathea. 1984. Role of midbrain raphe in stress-induced renin and prolactin secretion. Brain Res. 311:333-341.

30. Gotoh, E., K. Murakami, T. D. Bahnson, and W. F. Ganong. 1987. Role of brain serotoninergic pathways and hypothalamus in regulation of renin secretion. Am. J. Physiol. 253:R179-R185.

31. Kiss, A., and G. Aguilera. 1993. Regulation of hypothalamic pituitary adrenal axis during chronic stress: responses to repeated intraperitoneal hypertonic saline injection. Brain Res. 630:262-270.

32. Muller, J. 1993. Final steps of aldosterone biosynthesis: molecular solution of a physiological problem. J. Steroid Biochem. Mol. Biol. 45:153-159.

33. Crivello, J. F., and G. Gill. 1983. Induction of cultured bovine adrenocortical zona glomerulosa cell 17-hydroxylase activity by ACTH. Mol. Cell. Endocrinol. 30:97-107.

34. Braley, L. M., G. K. Adler, R. M. Mortensen, P. R. Conlin, R. Chen, J. Hallaham, A. I. Menachery, and G. H. Williams. 1992. Dose effect of adrenocorticotropin on aldosterone and cortisol biosynthesis in cultured bovine adrenal glomerulosa cells: in vitro correlate of hyperreninemic hypoaldosteronism. Endocrinology. 131:187-194.

35. Hauger, R. L., M. Lorang, M. Irwin, and G. Aguilera. 1990. CRF receptor regulation and sensitization of ACTH responses to acute ether stress during chronic intermittent immobilization stress. Brain Res. 532:34-40.

36. Harrison, L. C., and I. L. Campbell. 1988. Cytokines: an expanding network of immunoinflammatory hormones. Mol. Endocrinol. 2:1151-1156.

37. Aguilera, G., K. Fujita, and K. J. Catt. 1981. Mechanisms of inhibition of aldosterone secretion by adrenocorticotropin. Endocrinology. 108:522-528. 
38. Newton, M. A., and J. H. Laragh. 1968. Effect of corticotropin on aldosterone excretion and plasma renin activity in normal subjects, in essential hypertension and primary hyperaldosteronism. J. Clin. Endocrinol. \& Metab. 28:10061013.

39. Biglieri, E. G., M. Schambelan, and P. E. Slaton. 1969. Effect of adrenocorticotropin on deoxycorticosterone, corticosterone and aldosterone excretion. $J$. Clin. Endocrinol. \& Metab. 29:1090-1101.

40. Gaillard, R. C., A. M. Riondal, C. A. Favrod-Coune, and M. B. Vallaton. 1983. Aldosterone escape to chronic ACTH administration in man. Acta Endocrinol. 103:116-124.

41. Oelkers, W. 1985. Prolonged ACTH infusion supresses aldosterone secretion in spite of high renin activity. Acta Endocrinol. 108:91-97.

42. Aguilera, G., F. A. O. Mendelsohn, and J. K. Catt. 1984. Dopaminergic regulation of aldosterone secretion. Front. Neuroendocrinol. 8:265-291.

43. Beretta-Piccoli, C., P. Weidmann, A. Maier, M. Grimm, G. Keusch, and Z. Gluck. 1980. Effects of short term norepinephrine infusion on plasma catecholamines, renin and aldosterone in normal and hypertensive man. Hypertension (Dallas). 2:623-630.

44. Baretta-Piccoli, C., P. Weidman, K. Boehringer, L. Link, M. G. Bianchetti, and J. J. Morton. 1984. Relationship between plasma aldosterone and angiotensin II before and after noradrenergic inhibition in normal subjects and patients with mild essential hypertension. J. Clin. Endocrinol. \& Metab. 59:316-320.

45. Sequeira, S. J., and T. J. McKenna. 1985. Examination of the effects of epinephrine, norepinephrine and dopamine on aldosterone production in bovine glomerulosa cells in vitro. Endocrinology. 117:1947-1952.

46. DeLean, A., K. Pacz, N. McNicholl, and M. Desrosiers. 1984. Direct beta-adrenergic stimulation of aldosterone secretion in cultured bovine adrenal subcapsular cells. Endocrinology. 115:485-492.

47. Conlin, P. R. L. M. Braley, A. I. Menachery, N. K. Hollenberg, and G. H. Williams. 1992. Abnormal norepinephrine and aldosterone responses to upright posture in non-modulating hypertension. J. Clin. Endocrinol. \& Metab. 75:10171021.

48. Atlas, S. A., R. E. Volpe, R. E. Sosa, J. H. Laragh, M. J. F. Camargo, and T. Maack. 1986. Effects of atrial natriuretic peptide on blood pressure and the renin-angiotensin-aldosterone system. Fed. Proc. 45:2115-2121.

49. Natarajan, R. S. Ploszaj, R. Horton, and J. D. Nadler. 1989. Tumor necrosis factor and interleukin-1 are potent inhibitors of angiotensin II-induced aldosterone synthesis. Endocrinology. 125:3984-3089. 